Letter to editor

\title{
Physiology for Tomorrow
}

\section{Amin RA}

Physiology is a vast discipline in medical science. Physiology is for life. Where there is life there is physiology. The ultimate goal of physiology is to explain the physical and chemical factors that are responsible for the origin, development and progression of life. Therefore the field of physiology is too much vast from simple unicellular to multicellular organism, even complicated human life. The homeostatic mechanism, a nice mechanism to maintain healthy peaceful life, is the beauty of physiology. To achieve the target of physiology body has thousands of control system, including the negative feedback mechanism to maintain homeostatic state. Therefore the target of body mechanisms and all branches of medical science is to maintain proper physiological state for the healthy life.

Regarding the concept of 'Physiology for Tomorrow' we should learn physiology and enrich it further by dividing physiology into different branches and establishing a technology-led modern laboratory. For that purpose research, investigation, study, practical skill uplift must be required. We the physiologist have tremendous job to do for that purpose. All the physiologist all over the world must be united together sit together and work together to enrich the subject. It is important to remember that relationship of physiology with healthy safe life of human and rest of the living being is directly proportional. There is no doubt that physiology of future will have to be expertly managed.

To fulfill the above mentioned purpose the study of physiology can be divided into systemic and applied physiology and their sub-branches as well. A model central laboratory should be established with experts of physiology along with experts of other relevant disciplines to perform tests in a cost effective and efficient manner. Research of latest updates of physiology, in collaborative manner with SAARC countries, should be undertaken to enrich the subject.

The world community spends billions of dollars to a peaceful and healthy world. A major portion of that expenditure should be allocated for the development of physiology which is the basis and foundation of healthy life. May we invite the world population particularly physiologist 'please come forward to establish latest technology-led modern physiology to maintain safe and healthy life’.

\author{
Author Affiliations \\ Professor Dr Md Ruhul Amin \\ MBBS, M Phil \\ Professor and Head \\ Department of Physiology \\ Dhaka Medical College, Dhaka, Bangladesh
}

